Article

\title{
Structure and Properties of AlCrN Coatings Deposited Using Cathodic Arc Evaporation
}

\author{
Bogdan Warcholinski * $\mathbb{D}$, Adam Gilewicz, Piotr Myslinski, Ewa Dobruchowska ${ }^{\mathbb{D}}$ and \\ Dawid Murzynski \\ Faculty of Mechanical Engineering, Koszalin University of Technology, 75-453 Koszalin, Poland; \\ adam.gilewicz@tu.koszalin.pl (A.G.); piotr.myslinski@tu.koszalin.pl (P.M.); \\ ewa.dobruchowska@tu.koszalin.pl (E.D.); dawid.murzynski@tu.koszalin.pl (D.M.) \\ * Correspondence: bogdan.warcholinski@tu.koszalin.pl; Tel.: +48-94-3486-334
}

Received: 10 July 2020; Accepted: 13 August 2020; Published: 15 August 2020

check for updates Abstract: Al-Cr-N coatings were formed at various nitrogen pressures, substrate bias voltages and
substrate temperatures using cathodic arc evaporation. The relationship between technological
parameters and properties of the coatings was investigated. The phase and chemical composition
of the coatings, roughness, hardness, adhesion and thermal stability were analyzed by X-ray
diffraction (XRD), scanning electron microscope (SEM), Energy-dispersive X-ray spectroscopy (EDX),
micro-indenter, Rockwell, scratch tester and thermomechanical methods. The corrosion resistance
of selected coatings was also investigated. XRD analysis indicates that the coatings crystallize in a
cubic structure and show preferential orientation (200) CrN. With the increase of nitrogen pressure,
the preferential orientation changes to (111). EDX analysis shows that as nitrogen pressure increases,
the Al/(Al + Cr) rate decreases. Microscopic observations indicate that the number of macroparticles
reduces as nitrogen pressure increases. As a result, the surface roughness parameter Ra of the coatings
decreases. The effects of deposition temperature, nitrogen pressure and substrate bias voltage on
the mechanical and tribological properties of the coatings were investigated. It was found that the
above parameters influence the mechanical properties in different ways. The hardness and adhesion
of coatings formed at higher temperatures was lower. Coatings formed under a higher nitrogen
pressure or substrate bias voltage were characterized by higher hardness and better wear resistance.

Keywords: PVD coating; AlCrN; hardness; adhesion; roughness; thermal stability

\section{Introduction}

Chromium nitride coatings have found wide industrial applications due to their good mechanical and tribological properties and corrosion resistance [1,2]. However, their relatively low hardness as compared to the other coatings of transition metal nitrides reduces the area of their application-especially in tribology, in which the hardness is crucial. Additionally, for high-temperature applications, the thermal coating's stability determines the lifetime [3].

An addition to the two-component $\mathrm{Cr}-\mathrm{N}$ coatings, metallic and nonmetal elements can provide improvement in their properties, including increased hardness [4-7].

The coatings were deposited on separate $\mathrm{Al}$ and $\mathrm{Cr}$ cathodes $[6,8]$ and from alloy cathodes with the composition $\mathrm{Al}_{1-x} \mathrm{Cr}_{x} \mathrm{~N}$, where $x=0.2$ [9], 0.3 [7,10], 0.5 [11]. Another composition of cathodes was also used $[4,5,7,12-15]$. It was found that the hardness, oxidation resistance and tribological properties of $\mathrm{AlCrN}$ coatings improved with an increase of $\mathrm{Al}$ content, up to $70 \%-75 \%$ - as long as a face-centered cubic structure dominates $[4,15]$. This results in an increase in resistance to oxidation compared to the $\mathrm{CrN}$, TiN and TiAlN coatings and hardness stability up to temperature of $800{ }^{\circ} \mathrm{C}$ [2]. With the concentration of aluminum increase in the AlCrN coating AlN hexagonal phase (h-AlN) is formed. 
The presence of h-AlN in the coating reduces its mechanical properties [16]. h-AlN phase is more stable than the cubic phase, thus transformation c-AlN $\rightarrow$ h-AlN occurs spontaneously. Under the operating conditions of coated tools at elevated temperature there may be a phase transformation and mechanical properties of the coating can be deteriorated.

The properties of CrAlN coatings can be changed by selecting appropriate coating deposition parameters, including nitrogen pressure [9,14], AlCr-cathode composition $[4,15]$ and substrate bias voltage $[5,7,14]$. It has been shown that the microstructure and mechanical properties are strongly related to the cathode composition $[4,14]$ and the pressure of the reactive gas [11]. It was found that the application of the negative bias voltage to the substrate significantly affected the mechanical properties and the structure of the coatings [7]. Reiter et al. [4] indicates that with an increase of Al content to about $70 \%$ in the coating, the hardness increases to about 30\% and then decreases. An improved abrasion resistance compared to conventional TiN and TiAlN is also observed [4]. However, Aihua et al. [12] states that $\mathrm{CrAlN}$ and AlTiN coatings with high aluminum concentration, deposited by cathodic arc evaporation, do not show higher wear resistance compared to TiN and TiAlN.

The $\mathrm{AlCrN}$ coating exhibits excellent toughness at a high temperature and wear resistance under extreme conditions of mechanical stress and is used for tools for working gears, cylinders, stamps and forms. This coating is also dedicated to the treatment of hard-to-cut materials [17].

$\mathrm{AlCrN}$ coatings can be formed using various methods including magnetron sputtering from separate targets $\mathrm{Al}$ and $\mathrm{Cr}[6,7,18]$, HIPIMS [11] and cathodic evaporation $[4,5,7,9,13,19]$. Among the plasma-vacuum technologies, cathodic arc evaporation (CAE) is used more often. It is characterized by a high degree of plasma ionization and particle energy, which results in a high density of coatings and its good mechanical properties, including hardness and adhesion. The disadvantage of the method is a large number of surface defects, macroparticles and craters. Using the magnetron sputtering process, it is possible to obtain smooth coating surfaces. The low degree of plasma ionization results in a low coating density and, as a result, inferior mechanical properties compared to CAE [20].

The goal of this work was to determine the effect of $\mathrm{AlCrN}$ deposition parameters on the structural and mechanical properties including thermal stability determined by the thermomechanical analysis (TMA).

The coatings were deposited by cathodic arc evaporation on HS6-5-2 steel substrates. A variable parameters during the coating deposition were: the substrate bias voltage, nitrogen pressure and substrate temperature. The coating structure, deposition rate, chemical composition, hardness, adhesion and wear were studied.

\section{Materials and Methods}

\subsection{Coating Deposition}

AlCrN coatings were deposited using cathodic arc evaporation method in semi-industrial TINA 900 M system (Vakuumtechnik Dresden GmbH, Germany) equipped in arc sources with AlCr (50:50) alloy cathode with $99.995 \%$ purity. HS6-5-2 steel flat discs with $32 \mathrm{~mm}$ in diameter and cylindrical rods with $3 \mathrm{~mm}$ in diameter and $30 \mathrm{~mm}$ in length (for thermal stability testing) were applied as the substrates. Before deposition they were ground and polished to roughness parameter Ra about $0.02 \mu \mathrm{m}$. They were then ultrasonically cleaned in an alkaline bath to remove organic contaminations, rinsed in deionized water and dried in warm air. The substrates were placed on a rotating holder within the vacuum chamber at a distance of $18 \mathrm{~cm}$ from the arc sources. The planetary rotation about $2 \mathrm{rpm}$ was applied. The vacuum chamber was evacuated to pressure of $1 \mathrm{mPa}$. The next step prior to forming the coatings was an ion-etching of the substrate surface to remove surface oxides and to improve the adhesion of the coatings on the substrate. Ion etching using argon and chromium ions was carried out in an argon environment. In order to improve the adhesion of coatings on the substrate surface, a thin chromium layer with thickness of about $0.2 \mu \mathrm{m}$ was deposited. 
The $\mathrm{AlCrN}$ deposition process was carried out using the arc current of $80 \mathrm{~A}$. The coatings were prepared at substrate bias voltage $\left(U_{\mathrm{B}}\right)-100 \mathrm{~V}$ and nitrogen pressure in the chamber ranged from 1 to $5 \mathrm{~Pa}$. The deposition parameters are summarized in Table 1.

Table 1. Basic technological parameters for synthesizing AlCrN coatings.

\begin{tabular}{cccc}
\hline Parameter & Ion Etching & Adhesive Layer & AlCrN Coating \\
\hline AlCr cathode current & - & - & $80 \mathrm{~A}$ \\
Cr cathode current & $80 \mathrm{~A}$ & $80 \mathrm{~A}$ & - \\
Argon pressure & $0.5 \mathrm{~Pa}$ & $0.5 \mathrm{~Pa}$ & - \\
Nitrogen pressure & - & - & $1-5 \mathrm{~Pa}$ \\
Voltage & $-600 \mathrm{~V}$ & $-100 \mathrm{~V}$ & $-100 \mathrm{~V}$ \\
Deposition time & $10 \mathrm{~min}$ & $6 \mathrm{~min}$ & $120 \mathrm{~min}$ \\
Temperature & $350^{\circ} \mathrm{C}$ & $350^{\circ} \mathrm{C}$ & $350{ }^{\circ} \mathrm{C}$ \\
\hline
\end{tabular}

Additionally, the coatings were deposited using other technological parameters: substrate temperature of $450{ }^{\circ} \mathrm{C}$, substrate bias voltage ranging from 0 to $-300 \mathrm{~V}$. These coatings were not studied systematically.

The gas pressure and gas flow (argon, nitrogen) were controlled, respectively, using a Baratron type capacity gauge (MKS Instruments, Inc., Austin, TX, USA) and MKS flow controller (MKS Instruments, Inc., Austin, TX, USA).

\subsection{Characterization Methods}

X'Pert Panalytical device with $\mathrm{CuK} \alpha$ radiation was applied to register the $\mathrm{X}$-ray diffraction (XRD, Malvern Panalytical Ltd., Malvern, UK). The measurements were performed with a glancing angle $\left(\omega=3^{\circ}\right)$ and Bragg-Brentano geometry in the range of 2 theta angles between $30^{\circ}$ and $120^{\circ}$. The grain size was calculated using Scherrer's formula [21]. Due to instrumental peak broadening, $0.2^{\circ}$ for silicon standard, the Warren-Biscoe correction method was used [21].

Microstructure and surface morphology was measured by scanning electron microscopy (JEOL JSM-5500LV, JEOL Ltd., Tokyo, Japan). The Energy Dispersive X-ray Spectroscopy (EDS) and Wavelength-dispersive X-ray spectroscopy (WDS, thermo Fisher Scientific, Waltham, MA, USA) were applied to analyze the chemical composition of the coatings. Oxford Link ISIS 300 (Link Analytical/Oxford Instruments, High Wycombe, UK) and Noran Instruments IBEX systems (NORAN instruments, Inc., Middleton, WI, USA) were used, respectively.

Coating thickness was determined using spherical abrasion test. Hardness measurements were performed using Fischerscope ${ }^{\circledR}$ HM2000 microtester (Fischer Technology Inc., Windsor, CT, USA) equipped in WIN-HCU ${ }^{\circledR}$ software. Microhardness was determined with the fixed penetration depth of $0.3 \mu \mathrm{m}$, lower than $10 \%$ of coating thickness. It enables the correct measurement of coating hardness. Due to high roughness of the coating surface the procedure described by Romero et al. [5] including the coating surface polishing by fine-grained diamond powder $(2 \mu \mathrm{m})$ was used. After this operation, significantly reducing the surface roughness of the coating (to Ra $\sim .05 \mu \mathrm{m}$ ), the hardness was determined with a much smaller measurement uncertainty was applied. The hardness value was an average of 20 measurements.

Adhesion was assessed by Revetest scratch tester (CSM Instruments, Peseux, Switzerland) equipped with diamond indenter Rockwell type $C$ with a tip radius of $0.2 \mathrm{~mm}$. The indenter was moved with a sliding speed of $10 \mathrm{~mm} / \mathrm{min}$. Simultaneously, normal force increased linearly from 0 to $100 \mathrm{~N}$. Lc 1 critical load was determined as the load at which the first cracks in the coating appear and $\mathrm{Lc}_{2}$ critical load was defined as the load at which the total delamination of the coating from the substrate was observed. These loads were determined by observation using an optical microscope as the mean of at least three measurements. Adhesion was also evaluated using the Daimler-Benz test with a six-mode scale of adhesion quality [22]. According to this scale assigned to specific damage to the coating, HF1 to HF4 refer to relatively good adhesion with only few cracks or delamination close to 
contact with the Rockwell indenter. Notations HF5 and HF6 indicate poor adhesion with extensive spalling of the coating.

The surface roughness of the coatings was determined using contact profilometer Hommel Tester T8000 (Hommelwerke GmbH, Schwenningen, Germany). The test was performed five times for each sample.

The friction and wear of the coatings and counter-samples were determined by the ball-disk test. The test parameters are listed in Table 2.

Table 2. Parameters applied in ball-on-disc test.

\begin{tabular}{cc}
\hline Parameter & Value \\
\hline Normal load & $20 \mathrm{~N}$ \\
Sliding speed & $0.2 \mathrm{~m} / \mathrm{s}$ \\
Diameter of the track & $22 \mathrm{~mm}$ \\
Distance & $2000 \mathrm{~m}$ \\
Temperature & Room temperature \\
Humidity & $\mathrm{About} 40 \%_{2}$ \\
Counterpart type & $\mathrm{Al}_{2} \mathrm{O}_{3} \mathrm{ball}$ \\
Counterpart diameter & $10 \mathrm{~mm}$ \\
\hline
\end{tabular}

The wear rate $k v$ was evaluated from the equation: $k v=V /(s \cdot L)$, where $V$ is volume of the removed coating material, $s$ is the sliding distance and $L$ is the normal load [23]. To calculate the wear rate five randomly selected cross-sectional wear profiles were selected.

Corrosion resistance investigations were carried out using the potentiodynamic test to determine the corrosion potential $E_{\text {corr }}$, which is an indicator of the corrosion resistance of the material. The higher the corrosion potential, the more resistant the material to corrosion. The second parameter analyzed was the corrosive current density $i_{\text {corr }}$, which is directly proportional to the speed of the corrosion process. Based on the obtained potentiodynamic curves, the corrosion potential $\left(E_{\text {corr }}\right)$, the corrosion current density $\left(i_{\text {corr }}\right)$, the coefficients $b_{\mathrm{a}}$ and $b_{\mathrm{c}}$ being the slopes of the anode and cathode straight sections of Tafel and the value of polarization resistance $\left(R_{\mathrm{p}}\right)$ were determined using the Tafel method [24].

The corrosion susceptibility of the substrate-coating system was checked using the potentiodynamic method on the Atlas 0531 device (Atlas-Sollich, Rebiechowo/Gdansk, Poland). The tests were carried out in a three-electrode electrochemical cell according to the following assumptions:

- $\quad$ Reference electrode: calomel electrode $\mathrm{Hg} / \mathrm{Hg}_{2} \mathrm{Cl}_{2} / \mathrm{KCl}$; (SCE);

- Counter electrode: platinum electrode;

- Sample exposed surface: $0.292 \mathrm{~cm}^{2}$;

- Ambient temperature: $25 \pm 1{ }^{\circ} \mathrm{C}$;

- Electrolyte: $3.5 \%$ aqueous $\mathrm{NaCl}$ solution;

- Sample stabilization: measurement of the stationary potential in an open circuit during $1 \mathrm{~h}$ to obtain three reproducible results;

- Potential increase rate: $0.167 \mathrm{mV} / \mathrm{s}$;

- Potential range: reference sample: $-0.750 \mathrm{~V} \div-0.300 \mathrm{~V}$, substrate-coating: $-0.500 \mathrm{~V} \div 1.100 \mathrm{~V}$.

The tests of thermal stability of AlCrN coatings were conducted by modification of thermomechanical analysis known as DL TMA (dynamic load thermomechanical analysis) [25]. For thin-coating-substrate systems the object of measurements are the deformations of the cylindrical substrate occurring under the influence of temperature-dependent thermomechanical loads of the substrate by the deposited coating [26]. The source of these phenomena is the variable state of stress in the system due to thermal activation of a number of phenomena in the coating $[27,28]$. The substrate deformation is measured with a compensating dilatometer using temperature modulation [29]. The linear deformations of the substrate during heating are measured according to the thermogram shown in Figure 1. 


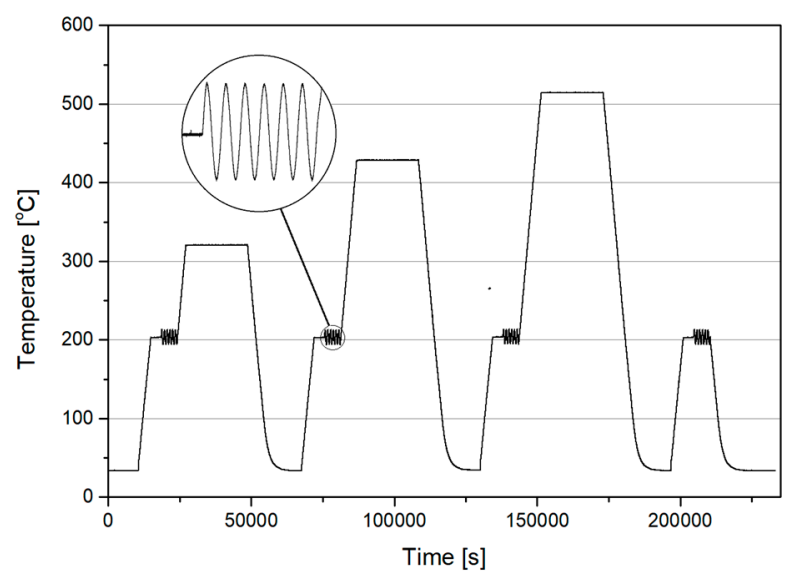

Figure 1. Thermogram to thermal stability diagnostics.

The samples were annealed successively at temperature $T_{\mathrm{a}}=320,430$, and $520^{\circ} \mathrm{C}$ for $3 \mathrm{~h}$ in the argon atmosphere. A characteristic feature of the testing method applied is that at the temperature of $200^{\circ} \mathrm{C}$. An isothermal heating sequence was used with a sinusoidal temperature modulation with an amplitude of $\pm 10^{\circ} \mathrm{C}$ and a period of $6 \mathrm{~min}$. The rate of linear temperature changes was $5^{\circ} \mathrm{C} / \mathrm{min}$.

The value of substrate linear expansion during heating depends both on the substrate material properties and the coating material applied, the adhesion of the coating to the substrate and the current value of stresses occurring in the tested coating $[28,30]$.

The applied metrological solution allows identification of the thermal stability of the thermomechanical loads of the substrate by determining changes in the values of two quantities: -at temperature above $150^{\circ} \mathrm{C}$-the effective coefficient of the substrate deformation $-\alpha_{\mathrm{DL}}$, -at temperature of $20^{\circ} \mathrm{C}$ of the fixed increase in the elongation of the substrate $\Delta L s$ after consecutive isothermal heating of the sample of the system successively at temperatures $T_{\mathrm{a}}=320,430$, and $520{ }^{\circ} \mathrm{C}$ according to the thermogram in Figure 1.

The $\alpha_{\mathrm{DL}}$ coefficient is a value depending on the current thermomechanical load of the substrate and is measured under temperature modulation conditions that is calculated from the equation:

$$
\alpha_{D L}=\frac{1}{L_{0}} \cdot\left(\frac{<A_{L}>}{A_{T}}\right),
$$

where: $\left\langle A_{\mathrm{L}}\right\rangle$ - the average amplitude of the cyclic changes in the elongation of the substrate temperature, $\left\langle A_{\mathrm{T}}\right\rangle$ - the average amplitude of the cyclic changes of the temperature modulation, $L_{0}$ - the substrate length at temperature $200^{\circ} \mathrm{C}$.

The proper measurement resolution for the measured values of substrate deformations is obtained by using temperature modulation [31]. Thermal stability of the thermomechanical interactions between the substrate and the coating was defined by determining the relative changes of substrate expansion coefficient $\alpha_{\mathrm{DL}}$ after subsequent heating cycles, measured at a temperature of $20{ }^{\circ} \mathrm{C}$ after annealing at temperature $T_{\mathrm{a}}=320,430$, and $520^{\circ} \mathrm{C}$ (Figure 1 ) which is calculated using formula:

$$
\Delta \alpha_{D L}=\frac{\alpha_{D L a}-\alpha_{D L d}}{\alpha_{D L d}} \cdot 100 \%,
$$

where: $\alpha_{\mathrm{DLa}}$-expansion coefficient of the coating-substrate system after annealing in selected temperature mentioned above, $\alpha_{\mathrm{DLd}}$-expansion coefficient of the coating-substrate system after coating deposition.

The values of fixed increments $\Delta L$ s after a given isothermal heating can also be used to describe the thermomechanical loads of the substrate of the examined system. For systems in which the compressive stress resides in the coating at $20^{\circ} \mathrm{C}$, the substrate is stretched under the influence of the deposited coating. As a consequence of thermal activation in the coating of a number of processes $[2,13,14,27,28]$, 
the state of stress in the system changes, whose metrological effect is the recorded change in the substrate length $\Delta L$ s related to the substrate length immediately after the adhesive coating is deposited. For a system where compressive stresses occur in the coating, a positive value of $\Delta L \mathrm{~s}$ after a given isothermal heating means an increase in compressive stress, while a negative value means a decrease in compressive stress. Changes in the absolute values of length increments $\Delta L s$ can be a quantitative measure of the thermal stability of the AlCrN coatings tested.

A consequence of the change in the stress state in the system is the increase in the length $\Delta L$ s of the substrate of the tested coating-substrate system after a given annealing. It is mainly caused by the thermal activation of a number of structural and chemical processes in the coating. They are treated as a source of changes in the dynamic load on the substrate by the deposited coating. Hence, the value of $\Delta L s$ measured at $20^{\circ} \mathrm{C}$ was adopted as a measure of the thermal stability of the coating structure. Modulated dilatometry enables the measurement of changes in the substrate length with the resolution appropriate for these changes, while maintaining specific metrological conditions.

\section{Results}

The thickness of the coatings deposited at temperature $350{ }^{\circ} \mathrm{C}$ was in the range of 4.5 to $6.0 \mu \mathrm{m}$ with maximum thickness for coating deposited in nitrogen pressure $3 \mathrm{~Pa}$. The coatings deposited at higher substrate temperature, $450{ }^{\circ} \mathrm{C}$, characterize by about $20 \%$ lower thickness ranged from 3.9 to $5 \mu \mathrm{m}$. For this substrate temperature the maximum thickness for coating deposited in nitrogen pressure $3 \mathrm{~Pa}$ was also observed. Due to the fact that deposition time of all coatings was the same, the deposition rates (Figure 2) are relevant.

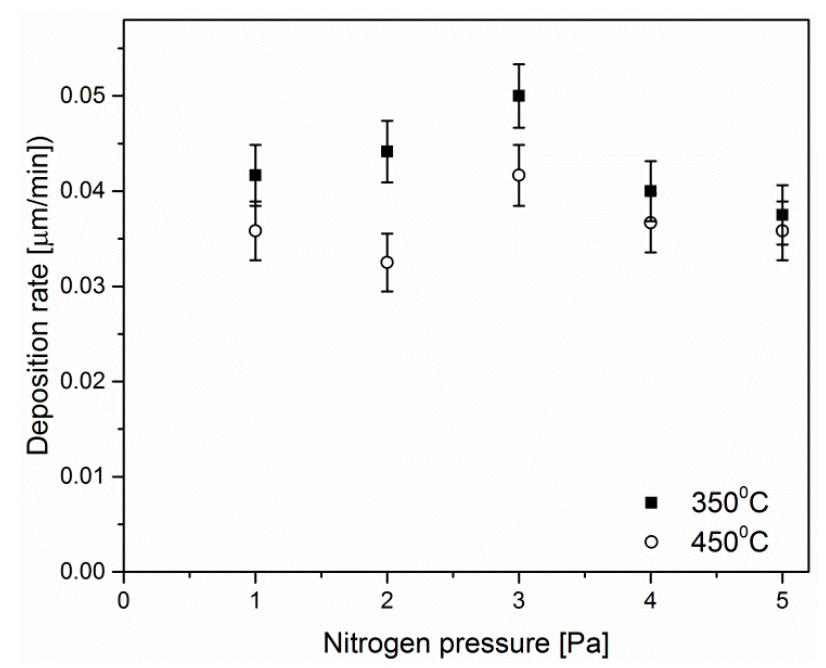

Figure 2. Deposition rates of AlCrN coatings formed at 350 and $450{ }^{\circ} \mathrm{C}$.

\subsection{Phase and Chemical Composition}

The typical XRD diffraction patterns of AlCrN coatings deposited at temperature of 350 and $450{ }^{\circ} \mathrm{C}$, negative substrate bias voltage $100 \mathrm{~V}$ and nitrogen pressure ranged from 1 to $5 \mathrm{~Pa}$ are shown in Figure 3 . The coatings crystallized in cubic CrN and AlN structure with main (111), (200) and (220) planes. The (311) and (222) planes with smaller intensity are also visible. In coating deposited at pressure of 1 Pa three phases can be identified: cubic CrN (ICDD 11-0065), cubic AlN (ICDD 46-1200) and $\mathrm{Al}_{3} \mathrm{Cr}_{7}$ (ICDD 03-065-6108). For nitrogen pressure higher than $2 \mathrm{~Pa} \mathrm{Al}_{3} \mathrm{Cr}_{7}$ phase decays. In coatings deposited at nitrogen pressure ranged from 3 to $5 \mathrm{~Pa}$ only $\mathrm{CrN}$ phase is observed. 

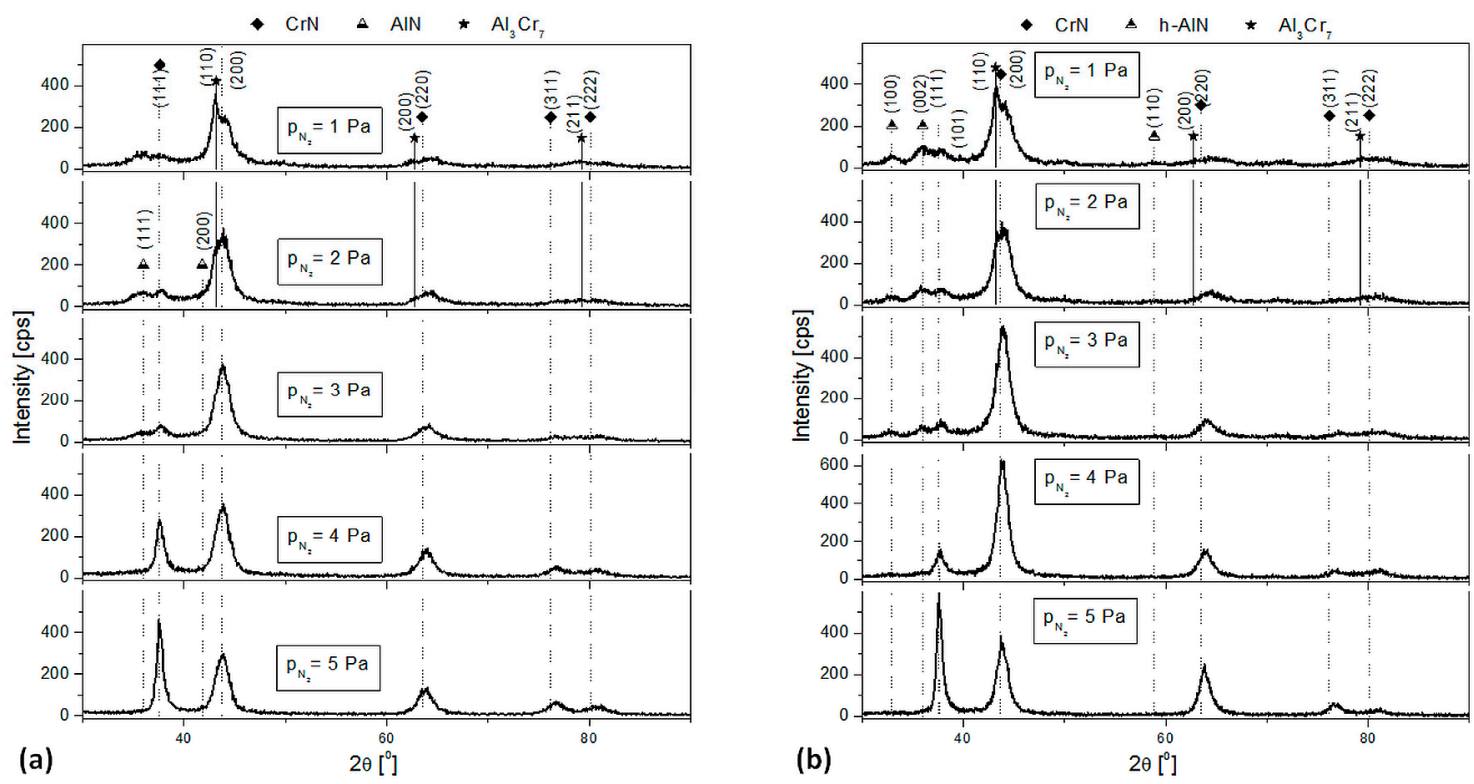

Figure 3. XRD diffraction patterns for $\mathrm{AlCrN}$ coatings deposited at negative substrate bias voltage $100 \mathrm{~V}$, various nitrogen pressure and temperatures. (a) $350{ }^{\circ} \mathrm{C}$; (b) $450{ }^{\circ} \mathrm{C}$.

The peak positions of $\mathrm{AlCrN}$ coatings agree with the powder diffraction pattern of $\mathrm{CrN}$. The intensity of the diffraction lines differs from the standard and depends on the nitrogen pressure during deposition. The preferred (200) $\mathrm{CrN}$ orientation is recognized in each coating. The peak positions are shifted to the higher angle. It can be explained by difference in lattice parameter for $\mathrm{CrN}$ $(0.4140 \mathrm{~nm})$ and $\operatorname{AlN}(0.4045 \mathrm{~nm})$. This shift can be related to relaxation of residual stress, as well as the formation of the h-AlN phase [4]. Peak positions of AlCrN coating exist at higher angle compared to $\mathrm{AlN}$. It can suggest that the investigated coatings form the solid solution $\mathrm{CrN}$ and $\mathrm{AlN}$ phases.

The coatings show preferential orientation in (111) and (200) planes. Such oriented coatings should be dense and adhesive to the substrate [32].

Careful observations of the diffraction lines in Figure $3 \mathrm{a}$ indicate that the lattice constant for coatings formed at $350^{\circ} \mathrm{C}$ increases from $0.4129 \mathrm{~nm}$ (3 Pa) to $0.432 \mathrm{~nm}$ (5 Pa). Simultaneously, the crystallite size in the coating, calculated from the plane (200), increases from $58 \mathrm{~nm}$ to $61 \mathrm{~nm}$, respectively. The position of this diffraction line is shifted towards higher angles related to the standard $\left(42.638^{\circ}\right)$ by about $0.2^{\circ}$. For coatings formed at $450{ }^{\circ} \mathrm{C}$ (Figure 3b), the position of the diffraction line (200) is shifted towards higher angles by approximately $0.3^{\circ}$. The lattice constant increases from $0.4118 \mathrm{~nm}(3 \mathrm{~Pa})$ to $0.4125 \mathrm{~nm}$ (5 Pa), and the size of the crystallites increases from $64 \mathrm{~nm}$ to $76 \mathrm{~nm}$, respectively. This means that in coatings formed at higher temperature, crystallites reach dimensions about $15 \%$ higher than crystallites present in the coatings formed at $350{ }^{\circ} \mathrm{C}$. Similar increase in lattice parameter with nitrogen was observed by Tang et al. [11].

An increase in substrate bias voltage results in change of coating structure, Figure 4 . For these coatings, a shift of the diffraction line (200) towards higher angles of about $0.3^{\circ}$ is also visible. An increase in the crystallite size to about $64 \mathrm{~nm}\left(U_{\mathrm{B}}=-150 \mathrm{~V}\right)$ is observed. It is associated with higher energy of bombarding ions, increasing temperature of the coating/substrate.

EDS measurement results confirm the presence of nitrogen, aluminum and chromium in the coatings. It should be also noted that in all the coatings about 0.5 at. $\%$ of oxygen was recorded. Analysis of the chemical composition of the coatings deposited at $350{ }^{\circ} \mathrm{C}$ with a negative substrate bias voltage of $100 \mathrm{~V}$ (Figure 5) indicates that increase in nitrogen pressure from 1 Pa to 5 results in increase of nitrogen concentration in the coatings from about 37 to 51 at.\%. Simultaneously, the decrease of aluminum and chromium concentration in the coatings is observed. 


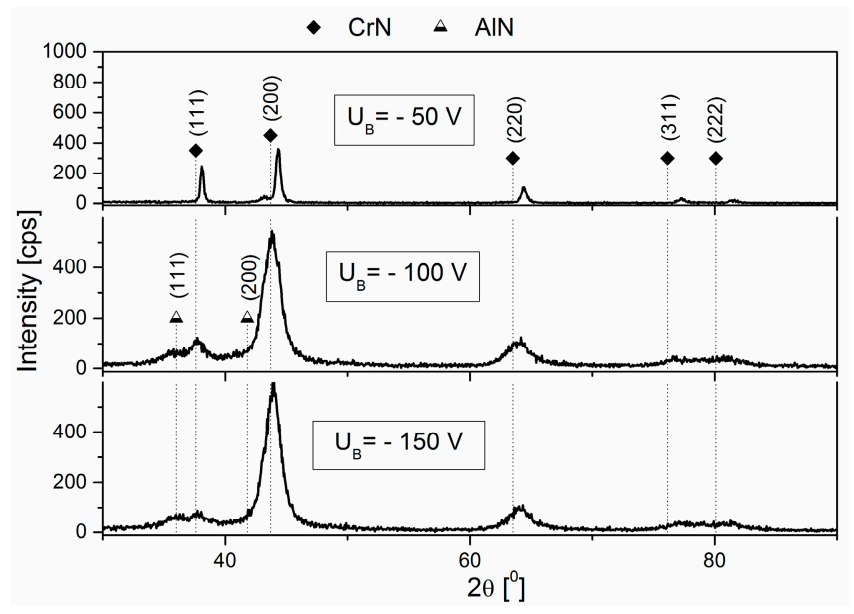

Figure 4. XRD diffraction patterns for $\mathrm{AlCrN}$ coatings deposited at temperature of $350^{\circ} \mathrm{C}$, nitrogen pressure of $3 \mathrm{~Pa}$ and various negative substrate bias voltages.

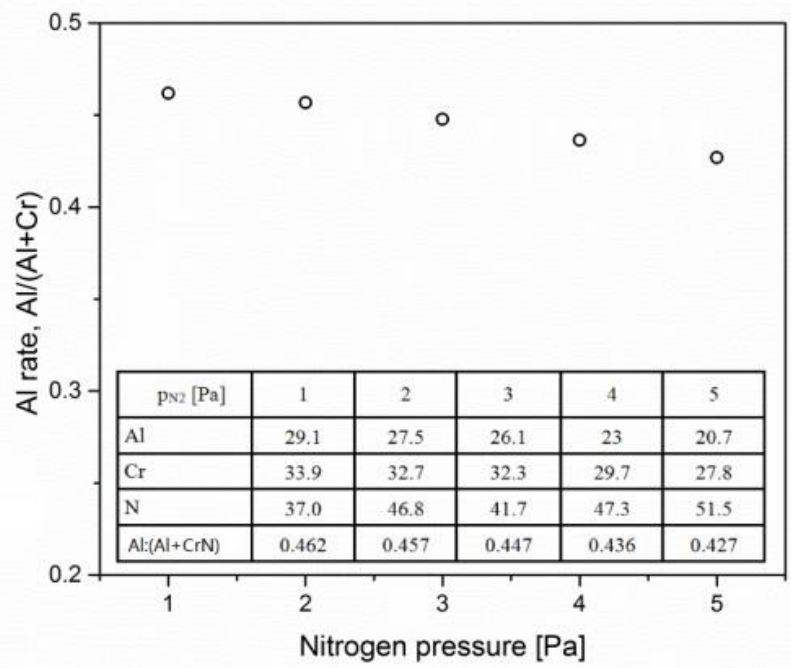

Figure 5. Al rate in $\mathrm{AlCrN}$ coatings deposited at temperature of $350{ }^{\circ} \mathrm{C}$, negative substrate bias voltage $100 \mathrm{~V}$ and various nitrogen pressure. Insert-chemical composition (at.\%) of coatings investigated.

EDS analysis is not very precise for light elements such as oxygen, nitrogen and carbon, and therefore the ratio of aluminum to chromium in the coating was calculated. This ratio is different from the composition of the cathode (50:50) and generally indicates loss of aluminum in the coating.

\subsection{Surface Morphology}

The disadvantage of an applied method of coating deposition, cathodic arc evaporation, is a large amount of macroparticles on the coating surface. During the arc process, the droplets emitted from the target arc spots may agglomerate to form macroparticles before reaching the coating surface [32]. On the surface of the coatings a large number of loosely adhered macroparticles with different sizes is observed, Figure 6. Craters at locations of removed macroparticles are also visible. The shape of the macroparticles is mainly spherical. Their size ranges from tenths of a micrometer to several micrometers, while most macroparticles, about $50 \%-60 \%$, are characterized by dimensions up to $1 \mu \mathrm{m}$, and a few reach dimensions even up to $10 \mu \mathrm{m}$. This effect was confirmed for TiAlN coating deposited by arc ion plating [32]. 

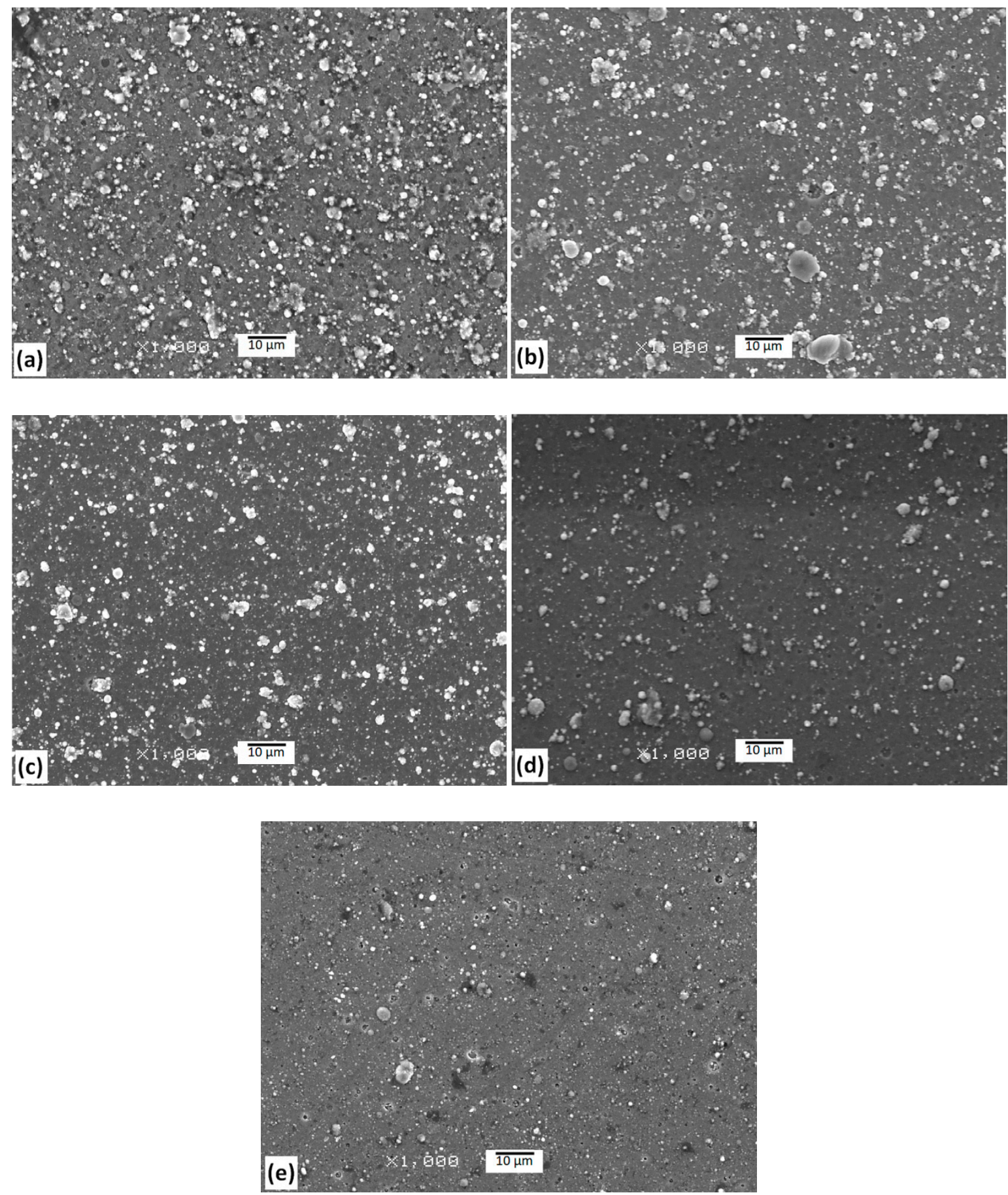

Figure 6. SEM images of $\mathrm{AlCrN}$ coatings deposited at $350{ }^{\circ} \mathrm{C}$ and different nitrogen pressure. (a) $1 \mathrm{~Pa}$; (b) $2 \mathrm{~Pa}$; (c) $3 \mathrm{~Pa}$; (d) $4 \mathrm{~Pa}$; (e) $5 \mathrm{~Pa}$.

The number of macroparticles decreases with increasing nitrogen pressure during the growth of the coatings. As a result, the roughness parameter Ra decreases (Figure 7). The relatively high Ra value is consistent with the results presented by Reiter et al. [13] on AlCrN coatings deposited using cathodic arc evaporation and Cai et al. [32] on AlTiN coatings. 


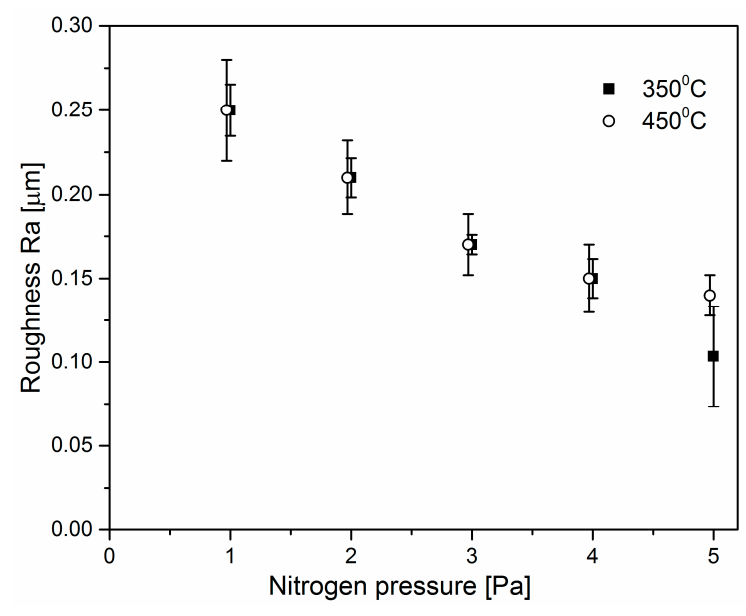

Figure 7. Roughness parameter $\left(R_{\mathrm{a}}\right)$ of $\mathrm{AlCrN}$ coatings.

The investigations of the coatings formed at the nitrogen pressure of $5 \mathrm{~Pa}$ and at different substrate bias voltages indicate that with increase of substrate bias voltage the deposition rate of the coating, as well as the surface roughness parameter $R_{\mathrm{a}}$ (arithmetic mean deviation of roughness profile) decrease, Figure 8.

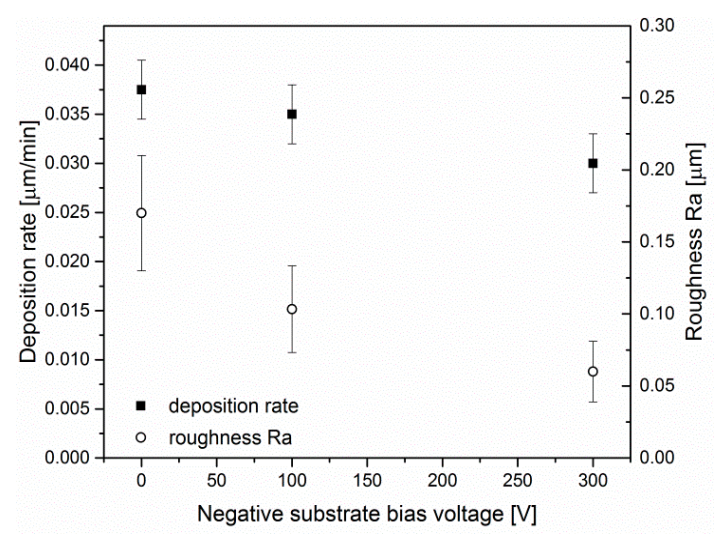

Figure 8. Deposition rate and roughness parameter $\left(R_{\mathrm{a}}\right)$ of $\mathrm{AlCrN}$ coatings deposited at substrate temperature of $350^{\circ} \mathrm{C}$ and nitrogen pressure $5 \mathrm{~Pa}$ at different substrate bias voltages.

\subsection{Hardness}

The coatings were deposited on the substrates heated to temperature of $350{ }^{\circ} \mathrm{C}$ using a nitrogen pressure from 1 to $5 \mathrm{~Pa}$. In Figure 9 an increase in the hardness of the coatings deposited at higher nitrogen pressures is visible.

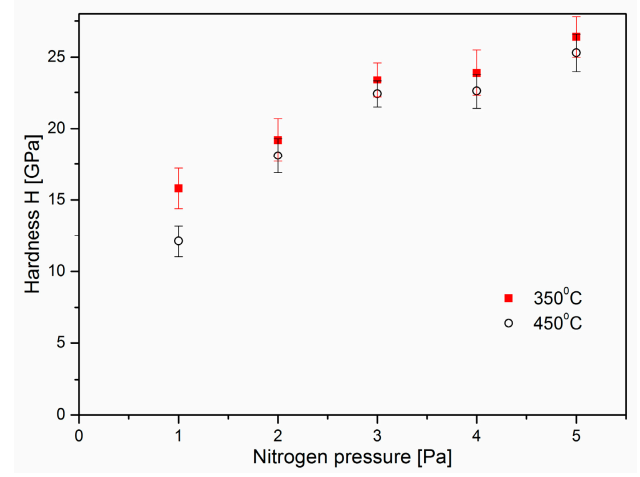

Figure 9. Hardness of $\mathrm{AlCrN}$ coatings formed at various nitrogen pressure. 
Not only hardness, but also deformation relative to yielding $(H / E)$ and resistance to the plastic deformation $\left(H^{3} / E^{2}\right)$ ratios $[33,34]$ can be significant indicators for tribological applications. The $H / E$ rate indicates the possible wear of the coating due to its hardness and allows a probable evaluation of the tribological properties of the materials. Better resistance of the coating on the deformation relative to yielding is connected with higher $H / E$ ratio. The higher $H^{3} / E^{2}$ ratio the higher resistance to plastic deformation. The $H / E$ and $H^{3} / E^{2}$ ratios are the lowest for the coating deposited under nitrogen pressure of $1 \mathrm{~Pa}$ and are 0.068 and 0.074 , respectively. They increase with nitrogen pressure during coating deposition and they reach the highest values for the AlCrN coating deposited under nitrogen pressure of $5 \mathrm{~Pa}, 0.94$ and 0.231 , respectively.

The substrate bias voltage has a significant effect on the growth and physical properties of the CrAlN coatings formed using cathodic arc evaporation. An increase in hardness with the negative substrate bias voltage is observed, Figure 10.

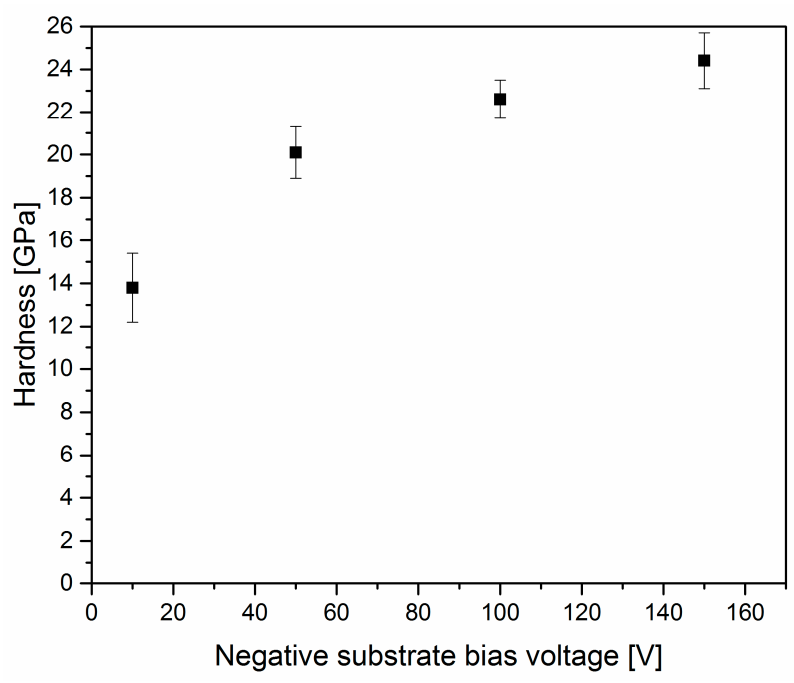

Figure 10. Hardness of $\mathrm{AlCrN}$ coatings deposited at temperature of $450{ }^{\circ} \mathrm{C}$ and nitrogen pressure of 3 Pa dependent on negative substrate bias voltage.

\subsection{Adhesion}

One of the most important feature of the coating-substrate system is adhesion. In recent years the scratch test is commonly applied because of the measurable (numeric) test result. Critical load $L_{\mathrm{c} 2}$ related to delamination of coatings formed in different nitrogen pressure and at the substrate bias voltage $-100 \mathrm{~V}$ is high-about 90 and $80 \mathrm{~N}$ for coatings deposited at $350{ }^{\circ} \mathrm{C}$ and about $450{ }^{\circ} \mathrm{C}$, respectively, Figure 11. Critical load is almost independent of the nitrogen pressure. Similar results of $L_{\mathrm{c}}$ are also reported in Ref [14,32].

It is assumed that $L_{\mathrm{c} 1}$ critical load is considered to be a resistance to crack initiation. For all coatings, both deposited at 350 and $450{ }^{\circ} \mathrm{C} \mathrm{Lc} 1$ ranges from 23 to $35 \mathrm{~N}$. For thin coatings the $L_{\mathrm{c} 1}$ value as high as possible is beneficial. Then the cracking of the coating occurs for higher loads. Zhang et al. [35] show that both high $\mathrm{Lc}_{1}$ and difference $\left(L_{\mathrm{c} 2}-L_{\mathrm{c} 1}\right)$ are necessary for high toughness of the coating. They proposed new parameter- $\mathrm{CPR}_{\mathrm{S}}$ (scratch crack propagation resistance) to evaluation of the film toughness: CPRs $=L_{\mathrm{c} 1} \cdot\left(L_{\mathrm{c} 2}-L_{\mathrm{c} 1}\right)$. Based on the equation, it was found that for coatings deposited at $350{ }^{\circ} \mathrm{C}$ the average value is about $1900 \mathrm{~N}^{2}$ and is the highest for coating deposited at nitrogen pressure $2 \mathrm{~Pa}$. Average value of $\mathrm{CPR}_{\mathrm{S}}$ for coatings deposited at $450{ }^{\circ} \mathrm{C}$ is about $30 \%$ lower and is about $1350 \mathrm{~N}^{2}$. In this set of coatings the highest value is for coating deposited at nitrogen pressure $3 \mathrm{~Pa}$. Above results are consistent with data shown in Figure 11.

The findings of Wang et al. [14] indicate that adhesion strength of $\mathrm{AlCrN}$ coatings is similar. $L c_{2}$ ranges from 60 to $85 \mathrm{~N}$ and Lc1 from 30 to $40 \mathrm{~N}$, depending on the substrate bias voltage and nitrogen pressure. Similar values are presented by Cai et al. [32] for Al-Ti-N coatings deposited using arc ion plating. 


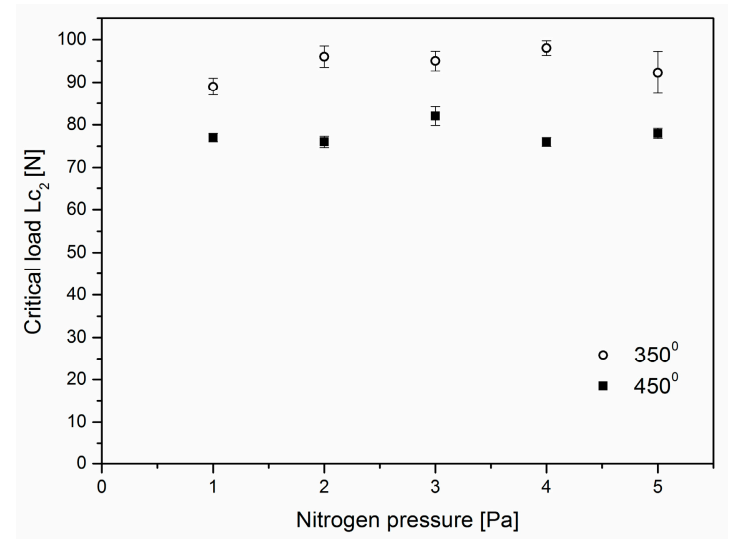

Figure 11. Critical load $\left(L_{\mathrm{c} 2}\right)$ of the coatings deposited using different nitrogen pressure and substrate bias voltage $U_{\mathrm{B}}=-100 \mathrm{~V}$.

The Daimler-Benz adhesion test is extremely quick and easy-to-apply test. The results of the test for coatings deposited at 350 and $450^{\circ} \mathrm{C}$ presenting the highest scratch crack propagation resistance $\left(C P R_{S}\right)$ are shown in Figure 12. The radial cracks extending out from the indent and spalling of the coatings are visible on coating deposited at $350^{\circ} \mathrm{C}$ (Figure 12a) and $450{ }^{\circ} \mathrm{C}$ (Figure 12b). Additionally, in Figure 12b the other type of coating damages, the cracks around indentation, are apparent. These cracks show cohesive microspallations along the length. $\mathrm{AlCrN}$ coating deposited at $450^{\circ} \mathrm{C}$ shows significantly more delamination. The results indicate that the coating adhesion can be classified as HF 2 to HF 3 for coating presented in Figure 12a and HF 3 to HF 4 for coating deposited at higher temperature (Figure 12b). Due to lower hardness of $\mathrm{AlCrN}$ coatings deposited at $450{ }^{\circ} \mathrm{C}$ pilling up around the indentation after the Daimler-Benz (DB) test forms. For this reason large tensile stresses may occur in its surrounding, which results in cracks around the indentation.

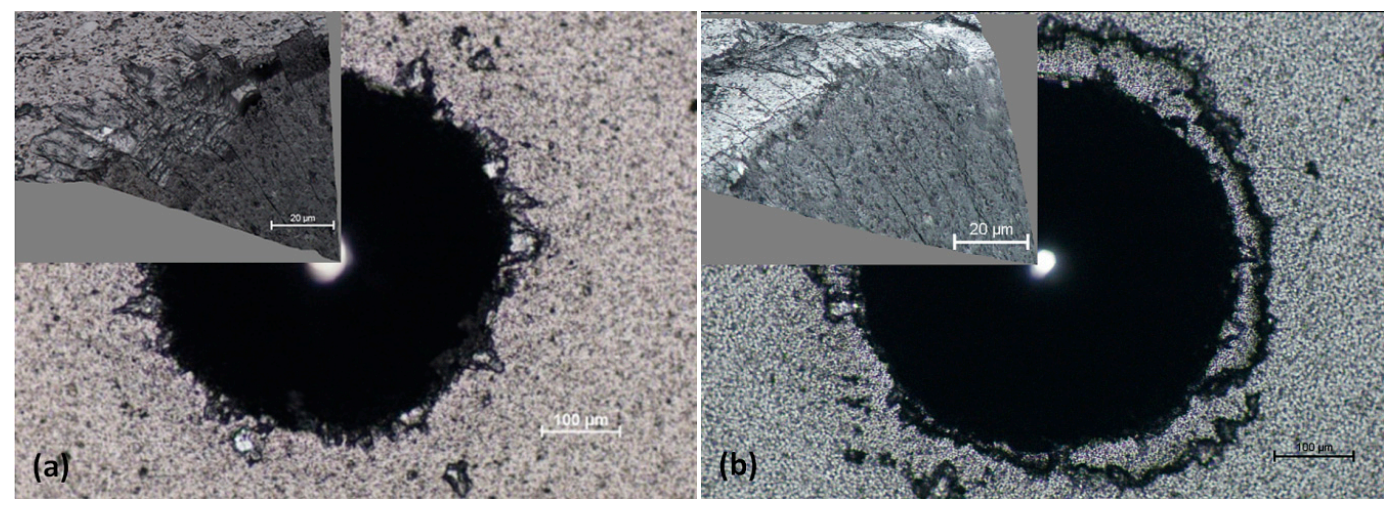

Figure 12. Micrographs of Rockwell indents in Daimler-Benz adhesion test for coatings, characterized by the highest scratch crack propagation resistance, deposited at: (a) $350{ }^{\circ} \mathrm{C}$ and $2 \mathrm{~Pa}$ and (b) $450{ }^{\circ} \mathrm{C}$ and $3 \mathrm{~Pa}$.

The hard coatings of good cohesion should exhibit-at most-small lines extending radially from the center of the indent to the outside. The indent crater should be also uncracked. In hard coating-substrate systems with good adhesion, there should be no delamination of the coating in the crater or surrounding area.

\subsection{Wear}

Figure 13 shows the wear rate of the coatings deposited at substrate temperature of $350{ }^{\circ} \mathrm{C}$, substrate bias voltage $U_{\mathrm{B}}=-100 \mathrm{~V}$ and different nitrogen pressure. Many parameters affect the wear rate of the coatings. These are the type of applied counterpart, normal load, sliding speed, 
test temperature, humidity, etc. Due to them, all the coatings were investigated under the same conditions. It is evident that the increase in nitrogen pressure during coating formation has a positive effect on their antiwear properties.

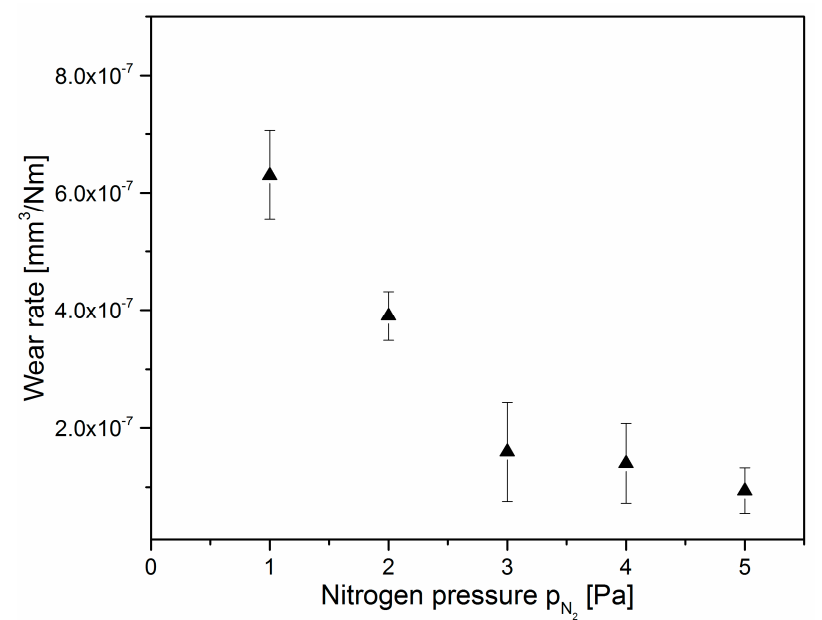

Figure 13. Wear rate of the coatings deposited using substrate temperature of $350{ }^{\circ} \mathrm{C}$, substrate bias voltage $U_{\mathrm{B}}=-100 \mathrm{~V}$ and different nitrogen pressure.

The wear is independent of coefficient of friction ranging from $0.62 \pm 0.02$ to $0.68 \pm 0.03$ against $\mathrm{Al}_{2} \mathrm{O}_{3}$ ball without clear trend. The wear rate of coatings formed under an atmosphere of nitrogen at $1 \mathrm{~Pa}$ is $6.3 \times 10^{-7} \mathrm{~mm}^{3} / \mathrm{Nm}$ decreases approximately 6 -fold to $9.4 \times 10^{-8} \mathrm{~mm}^{3} / \mathrm{Nm}\left(P_{\mathrm{N} 2}=5 \mathrm{~Pa}\right)$. It can be connected with significantly softer coating-hardness about $16 \mathrm{GPa}$ and its higher roughness. The coatings deposited at higher nitrogen pressure are characterized simultaneously by higher hardness and lower roughness. This is probably the reason for the decreasing coating wear rate.

The wear rate of $\mathrm{Al}_{2} \mathrm{O}_{3}$ counterpart is about two levels of magnitude lower than for coatings investigated. It is about $6 \times 10^{-9} \mathrm{~mm}^{3} / \mathrm{Nm}$ for the coating formed under nitrogen pressure of $1 \mathrm{~Pa}$ and decreases with increasing pressure to about $7 \times 10^{-10} \mathrm{~mm}^{3} / \mathrm{Nm}\left(P_{\mathrm{N} 2}=5 \mathrm{~Pa}\right)$. The images of selected counterparts wear are presented in Figure 14. They show abrasive wear. The wear diameter of the counterpart cooperating with the coating formed at a nitrogen pressure of $1 \mathrm{~Pa}$ is about $480 \mu \mathrm{m}$ and decreases to about $290 \mu \mathrm{m}$ for the coating deposited at $5 \mathrm{~Pa}$. Normal load, sliding distance and speed, as well as the circular track of 22-mm diameter against $\mathrm{Al}_{2} \mathrm{O}_{3}$ counterpart in the ball-on-disc test were the same.
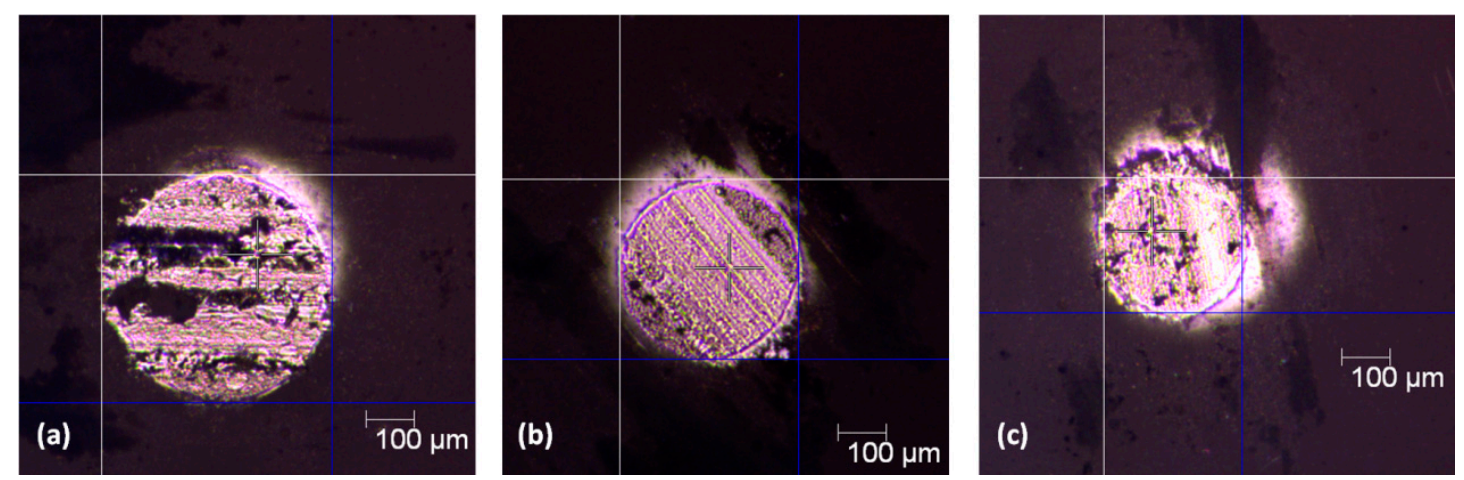

Figure 14. Wear of the counterpart- $\mathrm{Al}_{2} \mathrm{O}_{3}$ ball after a dry sliding wear test against coatings deposited at substrate temperature of $350{ }^{\circ} \mathrm{C}, U_{\mathrm{B}}=-100 \mathrm{~V}$ and nitrogen pressure. (a) $1 \mathrm{~Pa}$; (b) $3 \mathrm{~Pa}$; (c) $5 \mathrm{~Pa}$. 


\subsection{Corrosion}

The potentiodynamic tests showed that all AlCrN coatings significantly improve the corrosion resistance of HS6-5-2 steel, Figure 15. The change of nitrogen pressure in the coating process do not result in significant changes in the corrosion properties of the steel-coating system. Similar values of both corrosion potential and corrosion current density were registered. The best corrosion properties were obtained for the coating deposited at nitrogen pressure of $3 \mathrm{~Pa}$. The corrosion potential $E_{\mathrm{corr}}$ was $-0.010 \mathrm{~V}$ and the corrosion current density $i_{\text {corr }} 0.044 \mu \mathrm{A} / \mathrm{cm}^{2}$. However, it should be noted that the differences are small. All calculated parameters are presented in Table 3.

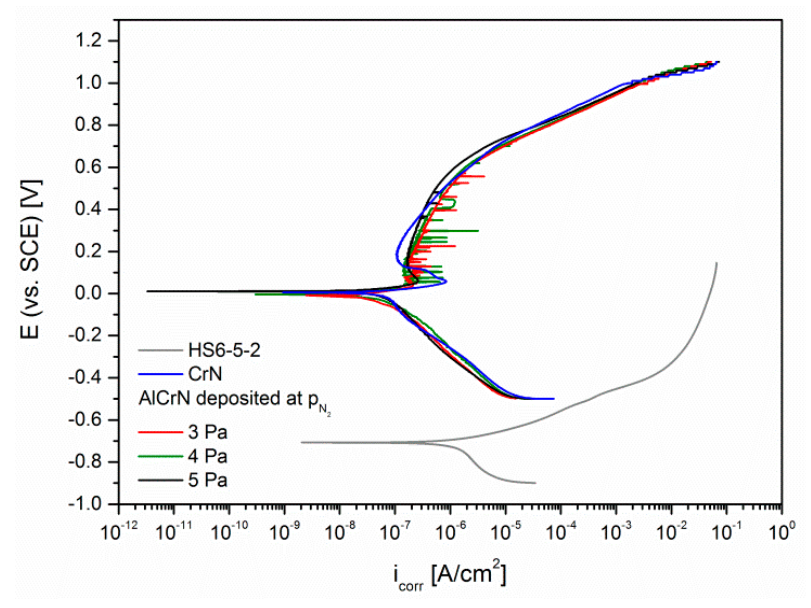

Figure 15. List of polarization curves for investigated coatings.

Table 3. Summary of all calculated parameters of the potentiodynamic corrosion tests.

\begin{tabular}{|c|c|c|c|c|c|c|}
\hline \multicolumn{2}{|c|}{ Sample } & $E_{\text {corr }}(\mathrm{V})$ & $i_{\text {corr }}\left(\mathrm{A} / \mathrm{cm}^{2}\right)$ & $R_{\mathrm{p}}\left(\mathrm{k} \Omega \cdot \mathrm{cm}^{2}\right)$ & $b_{\mathrm{a}}(\mathrm{V})$ & $b_{\mathrm{c}}(\mathrm{V})$ \\
\hline \multicolumn{2}{|c|}{ HS6-5-2 steel } & -0.702 & 2.8 & 13 & 0.080 & 0.380 \\
\hline \multicolumn{2}{|c|}{$\mathrm{CrN}$} & 0.002 & 0.053 & 256.01 & 0.036 & 0.229 \\
\hline \multirow{3}{*}{$\mathrm{AlCrN}$} & $P_{\mathrm{N} 2}=3 \mathrm{~Pa}$ & -0.010 & 0.044 & 439 & 0.061 & 0.169 \\
\hline & $P_{\mathrm{N} 2}=4 \mathrm{~Pa}$ & -0.014 & 0.103 & 419.32 & 0.170 & 0.235 \\
\hline & $P_{\mathrm{N} 2}=5 \mathrm{~Pa}$ & -0.007 & 0.065 & 339 & 0.070 & 0.188 \\
\hline
\end{tabular}

AlCrN coatings were also compared with $\mathrm{CrN}$ coating deposited at nitrogen pressure $P_{\mathrm{N} 2}=3 \mathrm{~Pa}$ and other parameters the same as for AlCrN coatings. The samples showed almost identical anti-corrosion properties, the difference in the corrosion potential is $0.003 \mathrm{~V}$, while in the corrosion current density $0.011 \mu \mathrm{A} / \mathrm{cm}^{2}$ in favor for $\mathrm{CrN}$ coating. There is also a noticeable difference in the course of the corrosion process. AlCrN samples show "noise" in the recording of anode current density, which was not recorded in the sample with the $\mathrm{CrN}$ coating applied. Current density fluctuations can, most likely, be attributed to alternating passivation and transpassivation processes occurring on the surface or in the vicinity of the microdroplets of Al. In addition, in the case of AlCrN coatings, a passive state was recorded in the potential range from 0.130 to $0.630 \mathrm{~V}$, which does not occur in the $\mathrm{CrN}$ coating.

In order to determine the resistance of the applied coatings to pitting corrosion, potentiodynamic cyclic tests were carried out, in which the sample was subjected to $12 \mathrm{~h}$ of stabilization in a corrosive environment. An example of a curve is shown in Figure 16. In all cases, similar curve runs and hysteresis loops were observed, which indicates a lack of pitting corrosion resistance. 


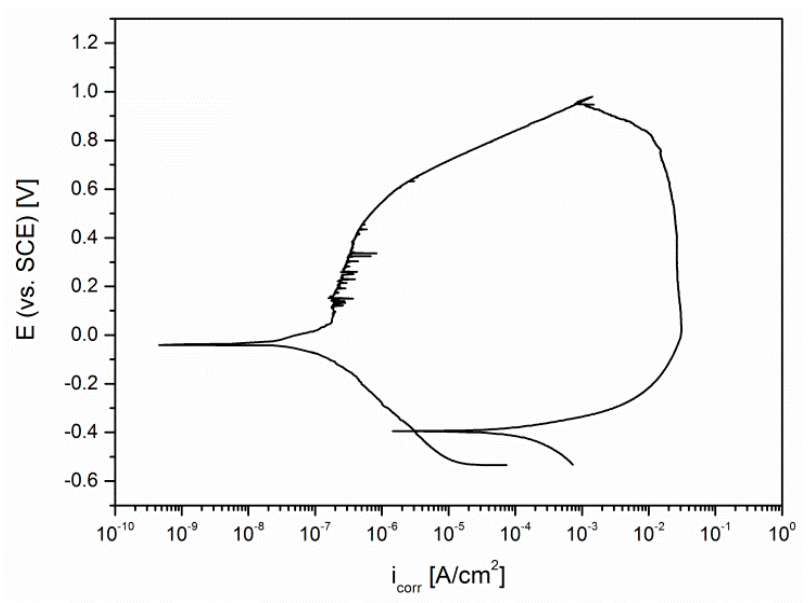

Figure 16. Measurement of pitting corrosion resistance for a coating formed at nitrogen pressure of $5 \mathrm{~Pa}$ on a steel HS6-5-2 substrate.

\subsection{Thermal Stability}

The thermal stability of $\mathrm{AlCrN}$ coatings formed at different nitrogen pressure in the vacuum chamber was investigated by controlled annealing according to the thermogram shown in Figure 1 . In Figure 17 is presented comparison of relative variations of the $\alpha$ coefficient at $200{ }^{\circ} \mathrm{C}$ for each coating, calculated according to Equations (1) and (2) after subsequent annealing at temperature $T_{\mathrm{a}}=320,430$, and $520^{\circ} \mathrm{C}$.

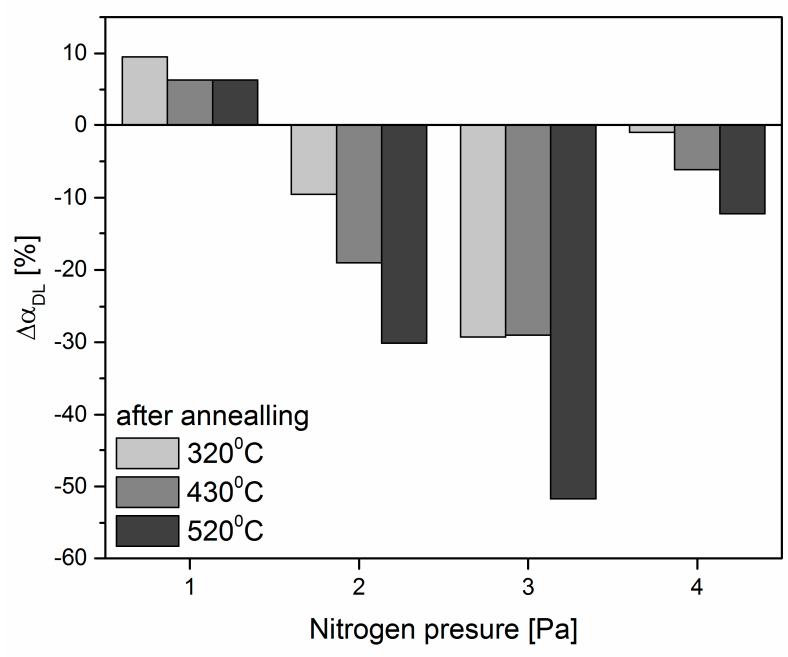

Figure 17. Result of thermal stability testing of AlCrN coatings formed at different nitrogen pressure in the technological chamber. Determined by means of relative changes in $\alpha_{\mathrm{DL}}$ coefficient at $200{ }^{\circ} \mathrm{C}$.

As described above in applied method positive values of $\Delta \alpha_{\mathrm{DL}}$ changes mean that the given annealing caused an increase in thermomechanical loads of the substrate through the coating, which is a consequence of the increase in the compressive stress in the coating. It relates for coating deposited at nitrogen pressure of $1 \mathrm{~Pa}$ annealed and $320^{\circ} \mathrm{C}$. With regard to the suitability of the analyzed coating-substrate system. This indicates the improvement of thermomechanical coupling conditions between these elements of the system. In the conditions of operation at elevated temperature. It may result in increased durability of these coatings. Negative values of $\Delta \alpha_{D L}$ changes mean loss of compressive stress value, which leads to deterioration of thermomechanical interaction conditions between the substrate and the coating. Which in turn affects the deterioration of the service life of the tested system. Such phenomena were recorded when coatings were deposited at nitrogen pressure 
$P=2,3$, and $4 \mathrm{~Pa}$. The coating-substrate system deposited at $P_{\mathrm{N} 2}=4$ Pa shows the most favorable stability. The obtained results of thermal stability tests of the coatings are qualitatively consistent with the test results of the temperature evolution of the stress in the AlCrN [36] and TiN coatings [37,38] deposited on a silicon substrate. In general, it can be assumed that the rule is used to interpret the results: the more negative value of the $\Delta \alpha_{\mathrm{DL}}$ changes, the less favorable operational lifetime forecast of the given system is.

In Figure 18 the results of the thermal stability tests of $\mathrm{AlCrN}$ coatings by registering the $\Delta L \mathrm{~s}$ values are shown. The results of measurements of $\Delta L$ s substrate length change after their subsequent annealing were applied. $\Delta L$ s measurements are performed at $20^{\circ} \mathrm{C}$ after each annealing. The coatings show compressive stresses. In this case, the analysis of the system service life based on $\Delta L$ s changes after the next annealing is carried out according to the rule: if after the given annealing a positive change of $\Delta L$ s occurred, the consequence of this annealing is the increase of compressive stresses and creation of conditions for increasing the service life of the tested system. The negative changes of $\Delta L s$ index after the annealing are the loss of compressive stresses in the coating, if the adhesion of the coating to the substrate has not changed. The qualitative compliance of the thermal stability of the tested systems, determined by the $\Delta \alpha_{\mathrm{DL}}$ coefficients measured at $200^{\circ} \mathrm{C}$, was registered.

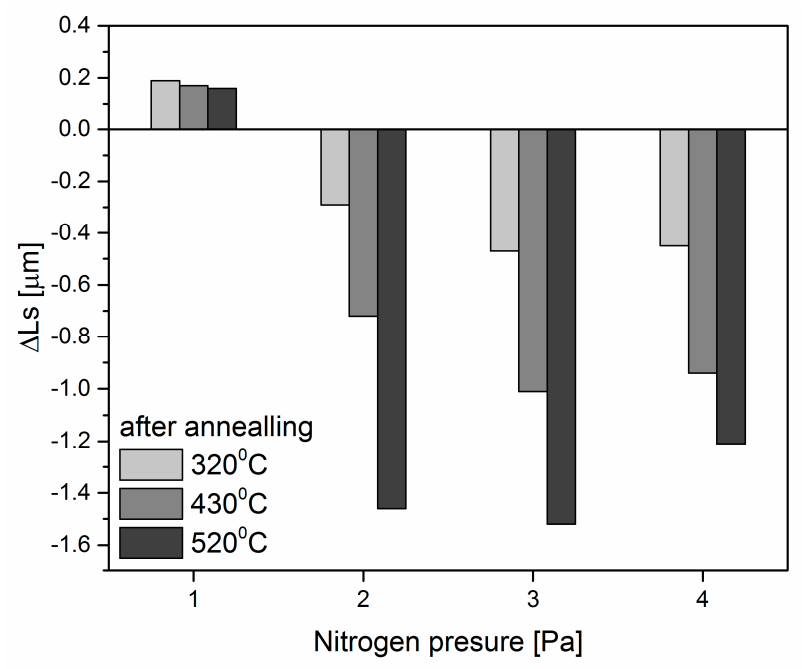

Figure 18. Changes in $\Delta L$ s index after annealing of tested AlCrN coating-substrate systems. $\Delta L$ s index was calculated from investigated system length measurements performed at $20^{\circ} \mathrm{C}$.

The qualitative differences in the values of the relative changes of $\Delta \alpha_{\mathrm{DL}}$ and $\Delta L$ s are consistent with the results of testing the functional parameters of AlCrN coatings [2,13,14].

\section{Discussion}

\subsection{Effect of Deposition Temperature}

The lower deposition rate for coatings deposited at higher temperature (Figure 2) may be explained by:

- So-called "target poisoning" [39]. When the nitride of the cathode material formed on the cathode has a higher melting point than the cathode, it can reduce the number of particles emitted from the arc spots;

- Other kinetics of the coating formation process. At higher substrate temperatures, the incident particles become more mobile, which can lead to easier resputtering.

The coatings formed at the temperature of $450{ }^{\circ} \mathrm{C}$ show a different phase composition, especially at lower nitrogen pressure, than the coatings formed at the temperature of $350^{\circ} \mathrm{C}$. Thus, the h-AlN phase is formed. As mentioned above, the crystallite size of the coatings deposited at the higher temperature 
$\left(450{ }^{\circ} \mathrm{C}\right)$ is about $10-25 \%$ greater than that of the coatings deposited at $350{ }^{\circ} \mathrm{C}$. This results in less hardness of these coatings. This effect is consistent with the Hall-Petch relation [40]:

$$
H=H_{0}+\frac{k_{H P}}{\Lambda^{0.5}}
$$

where: $H$-coating hardness, $H_{0}, k_{\mathrm{HP}}$-constants, $\Lambda$-grain size.

In this relation for greater crystallite size the hardness is smaller. The relatively low hardness of the coatings deposited at the nitrogen pressure of $1 \mathrm{~Pa}$ may be associated with the presence of $\alpha-\mathrm{Cr}$ phase, Figure 9. In a mixture of $\alpha-\mathrm{Cr}$ and $\mathrm{Cr}_{2} \mathrm{~N}$ hexagonal phases $\mathrm{Cr}$ phase is significantly softer. The increase in nitrogen pressure promotes the formation of $\mathrm{CrN}$ cubic phase [41]. Smaller hardness of the coatings deposited at higher temperature at lower nitrogen pressure is probably connected with phase composition. The coatings with h-AlN phase present significantly lower hardness [9].

$\mathrm{AlCrN}$ coatings characterized by a relatively low hardness of 10-20 GPa and increasing with negative substrate bias voltage increase were described by Wang et al. [18]. They indicate that low hardness may be caused by grains of relatively large size and the large number of defects resulting in a loose structure of the coating. Similar in hardness with nitrogen was observed by Tang et al. [11].

\subsection{Effect of Nitrogen Pressure}

The results of deposition rate, Figure 2 are consistent with the data presented elsewhere $[5,14,19]$. Cai et al. [32] indicate other relationship-increasing the deposition rate in nitrogen pressure from 0.7 to 1.2 Pa and decreasing from 1.2 to 1.7 Pa. Smaller thickness of the coatings deposited at a higher nitrogen pressure may result from the greater dissipation of ions due to collisions with gas particles [42].

With an increase in the nitrogen pressure during deposition process $\mathrm{Al}$ rate decreases, Figure 5. This may be related to the lower atomic mass of aluminum, which may result in greater dispersion of aluminum ions in comparison with chromium in collisions with nitrogen ions and leads to its lower condensation on the substrate. This effect was presented previously [10].

The findings of $\mathrm{Xu}$ et al. [43] indicate that $H^{3} / E^{2}$ ratio for $\mathrm{Al}_{0.68} \mathrm{Cr}_{0.32} \mathrm{~N}$ is about 0.09 . The investigations of $\mathrm{Cr}-\mathrm{Al}-\mathrm{N}$ coatings deposited using multi-arc ion plating conducted by Wang et al. [14] indicate that $H / E$ and $H^{3} / E^{2}$ ratios range from about 0.08 to 0.09 and from 0.20 to $0.23 \mathrm{GPa}$, respectively dependent on substrate bias voltage. Similar investigations on magnetron sputtered coatings show lower $H / E$ and $H^{3} / E^{2}$ ratios [18]. They range from 0.05 to 0.07 and from 0.02 to $0.12 \mathrm{GPa}$, respectively.

The wear rate of the coatings decreases from $6.3 \times 10^{-7} \mathrm{~mm}^{3} / \mathrm{Nm}\left(\mathrm{p}_{\mathrm{N} 2}=1 \mathrm{~Pa}\right)$ to $9.4 \times 10^{-8} \mathrm{~mm}^{3} / \mathrm{Nm}$ $\left(\mathrm{p}_{\mathrm{N} 2}=5 \mathrm{~Pa}\right)$. It can be connected with increasing hardness of the coatings. The course of changes in the wear rate with nitrogen pressure is similar to coatings formed from the AlCr cathode (80:20) [9]. Pulugurtha et al. [8] investigating CrAlN coatings deposited by AC reactive magnetron sputtering found similar phenomena. The increase in nitrogen flow rate in the vacuum chamber during their formation causes a decrease in the wear volume of the tested coating.

\subsection{Effect of Substrate Bias Voltage}

The smaller thickness of the coatings deposited at higher substrate bias voltage may result from the resputtering of the coating at which weakly bound particles are removed from the surface by high energy particles. As a result a change in the morphology and/or chemical composition of the coatings can be observed.

The energy of ions bombarding the substrate largely determines the nucleation and the growth of the coating as well as its quality. The changes the microstructure and properties of the coating, dependent on the parameters of the coating deposition, i.e., substrate bias voltage, the substrate temperature and the nitrogen pressure can be expected. The increase in ion energy (higher substrate bias voltage) contributes to the fine grain structure [14] with high hardness coatings (in some cases double the harder than the columnar structure). Additional features are as follows: a non-porous 
coating of high ductility and high adhesion to the substrate [44]. A small value of the substrate bias voltage favors the columnar structure formation of higher surface roughness [39]. It can be seen that for small substrate bias voltage the roughness parameter $R_{\mathrm{a}}$ of $\mathrm{AlCrN}$ coatings formed at $P_{\mathrm{N} 2}=5 \mathrm{~Pa}$ and substrate temperature of $350{ }^{\circ} \mathrm{C}$ (Figure 4$)$ is the largest, $(0.17 \pm 0.03) \mu \mathrm{m}$ and decreases to $(0.06 \pm 0.02)$ $\mu \mathrm{m}$ with increasing negative substrate bias voltage to about $-300 \mathrm{~V}$. A similar effect of reduction of the surface coating roughness with the substrate bias voltage increase was presented previously for $\mathrm{AlCrN}$ coating [5,13] and $\mathrm{CrN}[44-46]$.

It is probably connected with more dense and fine grained structure of the coatings deposited at higher negative voltage. This effect was earlier confirmed by Sabitzer et al. [7]. Due to reduction in the grain size the contribution of grain boundary fraction in the coating increases. In this case additional barriers for the lattice dislocation motion appear and it improves the strength of the coating [18]. The opposite effect is shown by Wang et al. [14] with an increase in the negative substrate bias voltage the hardness of the coating decreases. Such differing literature data may be related to different compositions of $\mathrm{AlCrN}$ coatings and probably the formation of other chromium (aluminum) nitride phases in the coatings.

\section{Conclusions}

The CrAlN coatings were deposited form cathode $\mathrm{Al}_{50} \mathrm{Cr}_{50}$ on HS6-5-2 steel substrates using cathodic arc evaporation. The effect of technological parameters: substrate temperature, nitrogen pressure, substrate bias voltage on chemical and phase composition and mechanical properties of the coatings were investigated. The above results allow to conclude as follows:

- The highest deposition rate was observed for coatings deposited at nitrogen pressure of three pascals independent of substrate temperature. The deposition rate was higher for coatings deposited at lower substrate temperature. The deposition rate decreased with negative substrate bias voltage increase. This was connected with coating resputtering phenomenon due to higher energy of bombarding ions;

- The roughness parameter $\mathrm{Ra}$ of the decreased with nitrogen pressure during deposition. The roughness Ra was similar for coatings deposited at substrate temperature 350 and $450{ }^{\circ} \mathrm{C}$. This was probably connected with the number of surface defects;

- The hardness of the coatings deposited in both temperatures 350 and $450^{\circ} \mathrm{C}$ increased with nitrogen pressure. Coatings deposited at higher temperature were characterized by lower hardness;

- The coatings were characterized by very good adhesion to the substrate. The critical force $L c_{2}$ was about $90 \mathrm{~N}$;

- The wear resistance of investigated coatings was dependent on nitrogen pressure during deposition. The coatings deposited at the highest nitrogen pressure showed the best wear resistance. Poor antiwear properties were observed for coatings formed at low nitrogen pressure;

- AlCrN coatings significantly improved the corrosion resistance of HS6-5-2 steel. The change of nitrogen pressure in deposition process did not significantly affect the course of the corrosion process; the differences in the obtained parameters were small. The best anti-corrosion properties were registered for the coating deposited at nitrogen pressure of three pascals. None of the coatings showed resistance to pitting corrosion. In all cases, hysteresis loops were observed in cyclic measurements;

- The results of thermomechanical tests of thermal stability of AlCrN coatings deposited with different nitrogen pressures in the technological chamber show that coatings deposited at nitrogen pressure of one pascal revealed the most favorable service life-provided that their operating temperature does not exceed $320^{\circ} \mathrm{C}$. In the group of coatings deposited at higher pressures and substrate polarization $U_{B}=-100 \mathrm{~V}$, the coatings deposited at a pressure of four pascals were particularly distinguished. They presented the most favorable thermal stability; the above coating properties were confirmed by the qualitative compliance of the two parameters $\alpha_{\mathrm{DL}}$ and $\Delta L s$. 
Author Contributions: Conceptualization, B.W. and A.G.; methodology, B.W.; software, D.M.; validation, B.W. and A.G.; formal analysis, B.W., A.G., P.M., E.D., and D.M.; resources, A.G.; data curation, B.W. and A.G.; writing - original draft preparation, B.W.; writing-review and editing, E.D. and A.G.; visualization, B.W. and E.D.; supervision, A.G. and P.M.; project administration, P.M.; funding acquisition, P.M. All authors have read and agreed to the published version of the manuscript.

Funding: This research was funded by the National Center for Research and Development, Poland, Grant Number Biostrateg3/344303/14/NCBR/2018. The APC was funded by Biostrateg3/344303/14/NCBR/2018

Conflicts of Interest: The authors declare no conflict of interest.

\section{References}

1. Mayrhofer, P.H.; HWillmann, H.; Mitterer, C. Oxidation kinetics of sputtered Cr-N hard coatings. Surf. Coat. Technol. 2001, 146, 222-228. [CrossRef]

2. Chim, Y.C.; Ding, Z.Z.; Zeng, X.T.; Zhang, S. Oxidation resistance of TiN. CrN. TiAlN and CrAlN coatings deposited by lateral rotating cathode arc. Thin Solid Films 2002, 517, 4845-4849. [CrossRef]

3. Mitterer, C.; Mayrhofer, P.H.; Musil, J. Thermal stability of PVD hard coatings. Vacuum 2003, 71, $279-284$. [CrossRef]

4. Reiter, A.E.; Derflinger, V.H.; Hanselmann, B.; Bachmann, T.; Sartory, B. Investigation of the properties of $\mathrm{Al}_{1-x} \mathrm{Cr}_{x} \mathrm{~N}$ coatings prepared by cathodic arc evaporation. Surf. Coat. Technol. 2005, 200, 2114-2122. [CrossRef]

5. Romero, J.; Gómez, M.A.; Esteve, J.; Montalà, F.; Carreras, L.; Grifol, M.; Lousa, A. CrAlN coatings deposited by cathodic arc evaporation at different substrate bias. Thin Solid Films 2006, 515, 113-117. [CrossRef]

6. Benlatreche, Y.; Nouveau, C.; Aknouch, H.; Imhoff, L.; Martin, N.; Gavoille, J.; Rousselot, C.; Rauch, J.Y.; Pilloud, D. Physical and mechanical properties of $\mathrm{CrAlN}$ and $\mathrm{CrSiN}$ ternary systems for wood machining applications. Plasma Phys. Polym. 2009, 6, S113-S119. [CrossRef]

7. Sabitzer, C.; Paulitsch, J.; Kolozsvári, S.; Rachbauer, R.; Mayrhofer, P.H. Influence of bias potential and layer arrangement on structure and mechanical properties of arc evaporated Al-Cr-N coatings. Vacuum 2014, 106, 49-52. [CrossRef]

8. Pulugurtha, S.R.; Bhat, D.G.; Gordon, M.H.; Shultz, J.; MJoshi, S.V.S.; Govindarajan, S. Mechanical and tribological properties of compositionally graded CrAlN films deposited by AC reactive magnetron sputtering. Surf. Coat. Technol. 2007, 202, 1160-1166. [CrossRef]

9. Gilewicz, A.; Jedrzejewski, R.; Myslinski, P.; Warcholinski, B. Structure, morphology and mechanical properties of AlCrN coatings deposited by cathodic arc evaporation. J. Mater. Eng. Perform. 2019, 28, 1522-1531. [CrossRef]

10. Birol, Y.; İsler, D. Response to thermal cycling of CAPVD (Al,Cr)N-coated hot work tool steel. Surf. Coat. Technol. 2010, 205, 275-280. [CrossRef]

11. Tang, J.F.; Lin, C.Y.; Yang, F.C.; Chang, C.L. Influence of nitrogen content and bias voltage on residual stress and the tribological and mechanical properties of CrAlN films. Coatings 2020, 10, 546. [CrossRef]

12. Aihua, L.; Jianxin, D.; Haibing, C.; Yangyang, C.; Jun, Z. Friction and wear properties of TiN, TiAlN, AlTiN and CrAlN PVD nitride coatings. Int. J. Refract. Met. Hard Mater. 2012, 31, 82-88. [CrossRef]

13. Reiter, A.E.; Mitterer, C.; de Figueiredo, M.R.; Franz, R. Abrasive and adhesive wear behavior of arc-evaporated $\mathrm{Al}_{1-x} \mathrm{Cr}_{x} \mathrm{~N}$ hard coatings. Tribol. Lett. 2010, 37, 605-611. [CrossRef]

14. Wang, L.; Zhang, S.; Chen, Z.; Li, J.; Li, M. Influence of deposition parameters on hard Cr-Al-N coatings deposited by multi-arc ion plating. Appl. Surf. Sci. 2012, 258, 3629-3636. [CrossRef]

15. Lin, J.; Mishra, B.; Moore, J.J.; Sproul, W.D. Microstructure, mechanical and tribological properties of $\mathrm{Cr}_{1-x} \mathrm{Al}_{x} \mathrm{~N}$ films deposited by pulsed-closed field unbalanced magnetron sputtering (P-CFUBMS). Surf. Coat. Technol. 2006, 201, 4329-4334. [CrossRef]

16. Forsén, R.; Johansson, M.P.; Odén, M.; Ghafoor, N. Effects of Ti alloying of AlCrN coatings on thermal stability and oxidation resistance. Thin Solid Films 2013, 534, 394-402. [CrossRef]

17. Endrino, J.L.; Fox-Rabinovich, G.S.; Gey, C. Hard AlTiN, AlCrN PVD coatings for machining of austenitic stainless steel. Surf. Coat. Technol. 2006, 200, 6840-6845. [CrossRef]

18. Wang, Y.X.; Zhang, S.; Lee, J.W.; Lew, W.S.; Li, B. Influence of bias voltage on the hardness and toughness of CrAlN coatings via magnetron sputtering. Surf. Coat. Technol. 2012, 206, 5103-5107. [CrossRef] 
19. Vetter, J.; Lugscheider, E.; Guerreiro, S.S. (Cr:Al) N coatings deposited by the cathodic vacuum are evaporation. Surf. Coat. Technol. 1998, 98, 1233-1239. [CrossRef]

20. Fuentes, G.G.; Rodriguez, R.; Avelar-Batista, J.C.; Housden, J.; Montal'a, F.; Carreras, L.J.; Cristobal, A.A.; Damborenea, J.J.; Tate, T.J. Recent advances in the chromium nitride PVD process for forming and machining surface protection. J. Mater. Proc. Technol. 2005, 167, 415-421. [CrossRef]

21. Cullity, B.D. Elements of X-ray Diffraction, 2nd ed.; Addison-Wesley Publishing Company Inc.: London, UK, 1978.

22. Vidakis, S.; Antoniadis, A.; Bilalis, N. The VDI 3198 indentation test evaluation of a reliable qualitative control for layered compounds. J. Mater. Process. Technol. 2003, 143, 481-485. [CrossRef]

23. Archard, F. Contact and rubbing of flat surface. J. Appl. Phys. 1953, 24, 981-988. [CrossRef]

24. McCafferty, E. Validation of corrosion rates measured by the Tafel extrapolation method. Corros. Sci. 2005, 47, 3202-3215. [CrossRef]

25. Wiedemann, H.; Riesen, R.; Boller, A. Elasticity characterization of materials during thermal treatment by thermal mechanical analysis. In Materials Characterization by Thermomechanical Analysis; Riga, A., Neag, M., Eds.; ASTM International: West Conshohocken, PA, USA, 1991; pp. 84-99.

26. Myśliński, P. Investigation of the thermal stability of hard coatings by Modulated Temperature Dilatometry. Vacuum 2009, 83, 757-760. [CrossRef]

27. Karlsson, L.; Hörling, A.; Johansson, M.P.; Hultman, L.; Ramanath, G. The influence of thermal annealing on residual stresses and mechanical propiertes of arc-evaporated $\operatorname{TiC}_{x} \mathrm{~N}_{1-x}(x=0,0.15$ and 0.45$)$ thin films. Acta Mater. 2002, 50, 5103-5114. [CrossRef]

28. Hultman, L.; Engström, C.; Birch, J.; Johannsson, M.P.; Oden, M. Review of the thermal and mechanical stability of TiN-based thin films. Z. Metallkd. 1999, 90, 803-813.

29. Price, D.M. Modulated-temperature thermomechanical analysis. Thermochim. Acta 2000, 357, $23-29$. [CrossRef]

30. Hultman, L. Thermal stability of nitride thin films. Vacuum 2000, 57, 1-30. [CrossRef]

31. Kraftmakher, Y. Modulation calorimetry and related techniques. Phys. Rep. 2002, 356, 1-117. [CrossRef]

32. Cai, F.; Zhang, S.; Li, J.; Chen, Z.; Li, M.; Wang, L. Effect of nitrogen partial pressure on Al-Ti-N films deposited by arc ion plating. Appl. Surf. Sci. 2011, 258, 1819-1825. [CrossRef]

33. Leyland, A.; Matthews, A. On the significance of the $H / E$ ratio in wear control: A nanocomposite coating approach to optimized tribological behaviour. Wear 2000, 246, 1-11. [CrossRef]

34. Musil, J.; Kunc, F.; Zeman, H.; Polakova, H. Relationships between hardness, Young's modulus and elastic recovery in hard nanocomposite coatings. Surf. Coat. Technol. 2002, 54, 304-313. [CrossRef]

35. Zhang, S.; Sun, D.; Fu, Y.; Du, H. Effect of sputtering target power on microstructure and mechanical properties of nanocomposite nc-TiN/a-SiN thin films. Thin Solid Films 2004, 447, 462-467. [CrossRef]

36. Tritremmel, C. Comparison of magnetron sputtering and arc evaporation by $\mathrm{Al}-\mathrm{Cr}-\mathrm{N}$ hard coating. Diploma Thesis, Montanuniversität Leoben, Leoben, Austria, 2007.

37. Bielawski, M.; Seo, D. Residual stress development in UMS TiN coatings. Surf. Coat. Technol. 2005, 200, 1476-1482. [CrossRef]

38. Bielawski, M. Residual stress control in TiN/Si coatings deposited by unbalance magnetron sputtering. Surf. Coat. Technol. 2006, 200, 3987-3995. [CrossRef]

39. Wan, X.S.; Zhao, S.S.; Yang, Y.; Gong, J.; Sun, C. Effects of nitrogen pressure and pulse bias voltage on the properties of Cr-N coatings deposited by arc ion plating. Surf. Coat. Technol. 2010, 204, 1800-1810. [CrossRef]

40. Taha, A.S.; Hammad, F.H. Application of the Hall-Petch relation to microhardness measurements on $\mathrm{Al}, \mathrm{Cu}$, Al-MD 105, and Al-Cu Alloys. Phys. Status Solidi 1990, 119, 455-462. [CrossRef]

41. Rebholz, C.; Ziegele, H.; Leyland, A.; Matthew, A. Structure, mechanical and tribological properties of nitrogen-containing chromium coatings prepared by reactive magnetron sputtering. Surf. Coat. Technol. 1999, 115, 222-229. [CrossRef]

42. Choi, S.A.; Kim, S.W.; Lee, S.M.; Kim, H.T.; Oh, Y.S. Effect of working pressure and substrate bias on phase formation and microstructure of Cr-Al-N coatings. J. Korean Ceram. Soc. 2017, 54, 511-517. [CrossRef]

43. Xu, Y.X.; Riedl, H.; Holec, D.; Chen, L.; Du, Y.; Mayrhofer, P. Thermal stability and oxidation resistance of sputtered Ti-Al-Cr-N hard coatings. Surf. Coat. Technol. 2017, 324, 48-56. [CrossRef]

44. Oden, M.; Almer, J.; Hakansson, G. The effects of bias voltage and annealing on the microstructure and residual stress of arc-evaporated Cr-N coatings. Surf. Coat. Technol. 1999, 120, 272-276. [CrossRef] 
45. Wang, D.Y.; Weng, K.W. Deposition of CrN coatings by current-modulating cathodic arc evaporation. Surf. Coat. Technol. 2001, 137, 31-37. [CrossRef]

46. Lin, J.; Sproul, W.D.; Moore, J.J.; Wu, Z.L.; Lee, S.L. Effect of negative substrate bias voltage on the structure and properties of $\mathrm{CrN}$ films deposited by modulated pulsed power (MPP) magnetron sputtering. J. Phys. D Appl. Phys. 2011, 44, 425305. [CrossRef] 